\title{
EFEKTIFITAS ELEKTRONIK EARLY WARNING SYSTEM DALAM IDENTIFIKASI PERBURUKAN NEONATUS DI UNIT PERAWATAN INTENSIF: STUDI LITERATUR REVIEW
}

\author{
Kurniaty Ika Sari Tobing ${ }^{1}$ (NPM. 1806170536) \\ Program Studi Magister Keperawatan Fakultas Ilmu Keperawatan Universitas Indonesia \\ *Email: brave4kiki@gmail.com
}

\begin{abstract}
Abstrak
Penggunaan early warning system pada neonatal di unit perawatan intensif secara elektronik dapat membantu memberikan informasi yang adekuat dan berkelanjutan terhadap pengambilan keputusan klinis sehingga penatalaksanaan yang diberikan pada neonatal secara tepat dan cepat. Hal ini penting untuk dikembangkan karena neonatal merupakan kelompok usia yang sangat rentan terjadinya perburukan klinis dan sangat cepat untuk terjadinya kegagalan fungsi organ hingga kematian. Informasi terkait dilakukan pencarian jurnal dari researchgate, ebsco, sage hingga google scholar dengan kata kunci early, electronics, deterioration, neonatal, warning, dan ditemukan sepuluh jurnal terkait dengan rentang waktu publikasi dari tahun 2008 hingga 2018. Penggunaan elektronik neonatal early warning system dan aplikasi skor 'HeRo' (Heart Rate Observation) dalam mengidentifikasi dini kondisi perburukan klinis neonatal di unit perawatan intensif menunjukkan penurunan signifikan terhadap angka kesakitan, kematian dan lama perawatan intensif.
\end{abstract}

Kata kunci: early, electronics, deterioration, neonatal, warning

\begin{abstract}
The use of electronic early warning system in neonatal intensive care unit can help provide adequate and sustainable information on clinical decision making the intervention delivered to neonatal with appropriately and quickly. This is important to develop because neonatal is an age group that is very susceptible to clinical deterioration, organ failure and mortality. Related information is carried out by searching journals from researchgate, ebsco, sage to google scholar with keyword 'at-risk, early, electronics, deterioration, neonatal, NICU, system, trigger, warning', within publication period from 2008 to 2018. Only 10 journals related to this subject. The use of electronic neonatal early warning systems and the application of 'Heart Rate Observation' (HeRo) scores in identifying early neonatal clinical deterioration conditions in the intensive care unit shows a significant reduction in morbidity, mortality and length of intensive care.
\end{abstract}

Keyword: early, electronics, deterioration, neonatal, warning

\section{Pendahuluan}

Neonatus merupakan kelompok usia rentan yang seringkali mengalami dekompensasi akut dari beragam penyebab, dimana neonatus memiliki rentang respon yang terbatas terhadap gangguan fisiologis sehingga tandatanda yang muncul dapat menjadi tidak spesifik. (Kim, Brousseau, \& Konduri, 2008). Neonatus akan dihadapkan pada resiko perburukan klinis sebagai hasil dari beragam faktor seperti proses adaptasi pada lingkungan kehidupan ekstrauterin, immaturity fisiologis (terkait dengan usia gestasi) atau paparan dari resiko intrapartum seperti infeksi. 
(Paliwoda \& New, 2015). Menghadapi

fluktuasi kondisi klinis neonatal terutama di unit perawatan intensif dapat terjadi kegagalan dalam mengidentifikasi perburukan klinis yang sedang terjadi karena tidak spesifiknya tanda dan gejala yang ditunjukkan neonatus sehingga sulit dikenali.

Salah satu upaya yang dikembangkan adalah dengan meningkatkan reabilitas tekhnologi sistem informasi yang sudah ada dengan penambahan aplikasi skoring 'at-risk' yang sesuai dengan fisiologis neonatal. Analisa monitoring perubahan terhadap kondisi fisiologis dapat mengantisipasi kondisi klinis menjadi lebih buruk (Schwartz, 2016). Sistem informasi pada rekam medis elektronik di unit perawatan intensif neonatal memerlukan tampilan data perkembangan klinis secara menyeluruh (Davison \& Birch, 2008), sehingga dapat memberikan kepadatan informasi yang dibutuhkan dalam pembuatan keputusan klinis pasien (Ellsworth, Lang, Pickering, \& Herasevich, 2014).

Pada penelitian yang dilakukan oleh Jones et al pada tahun 2011 menunjukkan bahwa keakuratan penghitungan secara elektronik skor early warning meningkat dari $81 \%$ menjadi $100 \%$, dan berkurangnya hari rawat pasien dengan rata-rata 7 hari dari semula 10 hari. Penambahan aplikasi notifikasi pada elektronik early warning system (EWS) menunjukkan peningkatan kehadiran respon tanggap dari petugas medis untuk skor EWS 3, 4, 5 sebesar $78 \%$ dari sebelumnya $29 \%$, sedangkan pada skor lebih dari 5 meningkat hingga $96 \%$ dari $67 \%$ (Jones et al., 2011).

Penelitian lain yang bertujuan dalam mengidentifikasi kondisi perburukan klinis neonatal adalah dengan skoring Heart Rate Observation (HeRo) dalam melakukan monitoring tanda vital di unit perawatan intensif adalah yang dilakukan oleh K. Fairchild \& Aschner (2012) didapatkan hasil bahwa pasien yang dilakukan metode skor 'HeRo' memiliki rata-rata 2,3 hari hidup lebih lama dan tidak terpasang ventilasi mekanik dibanding pasien yang tidak dilakukan pemasangan skor 'HeRo' pada monitornya, angka mortalitas lebih rendah $22 \%$ pada kelompok yang memiliki tampilan 'HeRo' dibandingkan dengan kelompok yang tidak memiliki tampilan 'HeRo', kemudian menurunnya mortalitas pada neonatal yang terdiagnosa sepsis (pada neonatal yang menunjukkan hasil kultur 
darah yang positif) sebanyak $4 \%$ ketika diterapkan metode skor 'HeRo'.

Penulisan artikel ini memberikan referensi terhadap penggunaan sistem skoring resiko sebagai identifikasi dini dari kondisi perburukan klinis secara elektronik yang dilakukan pada neonatus di unit perawatan intensif terhadap penurunan angka morbiditas, mortalitas dan lama perawatan intensif, sehingga mendukung peningkatan mutu layanan kesehatan anak terutama neonatal.

\section{Metode}

Dilakukan pencarian jurnal tahun 2012 hingga 2018, namun dikarenakan masih minimnya jurnal terkait, maka pencarian dilakukan dari tahun 2008 hingga 2018, dengan kata kunci: early, electronics, deterioration, neonatal, warning, pada database researchgate, sage, hingga google scholar, kemudian didapatkan 10 jurnal yang terkait. Kriteria inklusi dari pencarian ini adalah artikel original, dan studi literatur review tentang manfaat identifikasi dini kondisi perburukan klinis neonatal dengan menggunakan elektronik sistem skoring 'at-risk' di unit perawatan intensif. Tujuan dari penulisan artikel ini adalah melihat pemanfaatan early warning system terhadap penurunan morbiditas, mortalitas serta lama perawatan intensif.

\section{Hasil}

Elektronik Neonatal Early Warning System (NEWS)

Penilaian dengan early warning system mendasarkan pada pengamatan fisiologis (salah satunya adalah denyut jantung dan laju nafas) sebagai salah satu cara dalam identifikasi perburukan kondisi klinis neonatal untuk menunjang penatalaksanaan asuhan yang tepat dan cepat sehingga dapat menurunkan angka morbiditas dan mortalitas neonatal. (Roland, Madar, \& Connolly, 2010). 


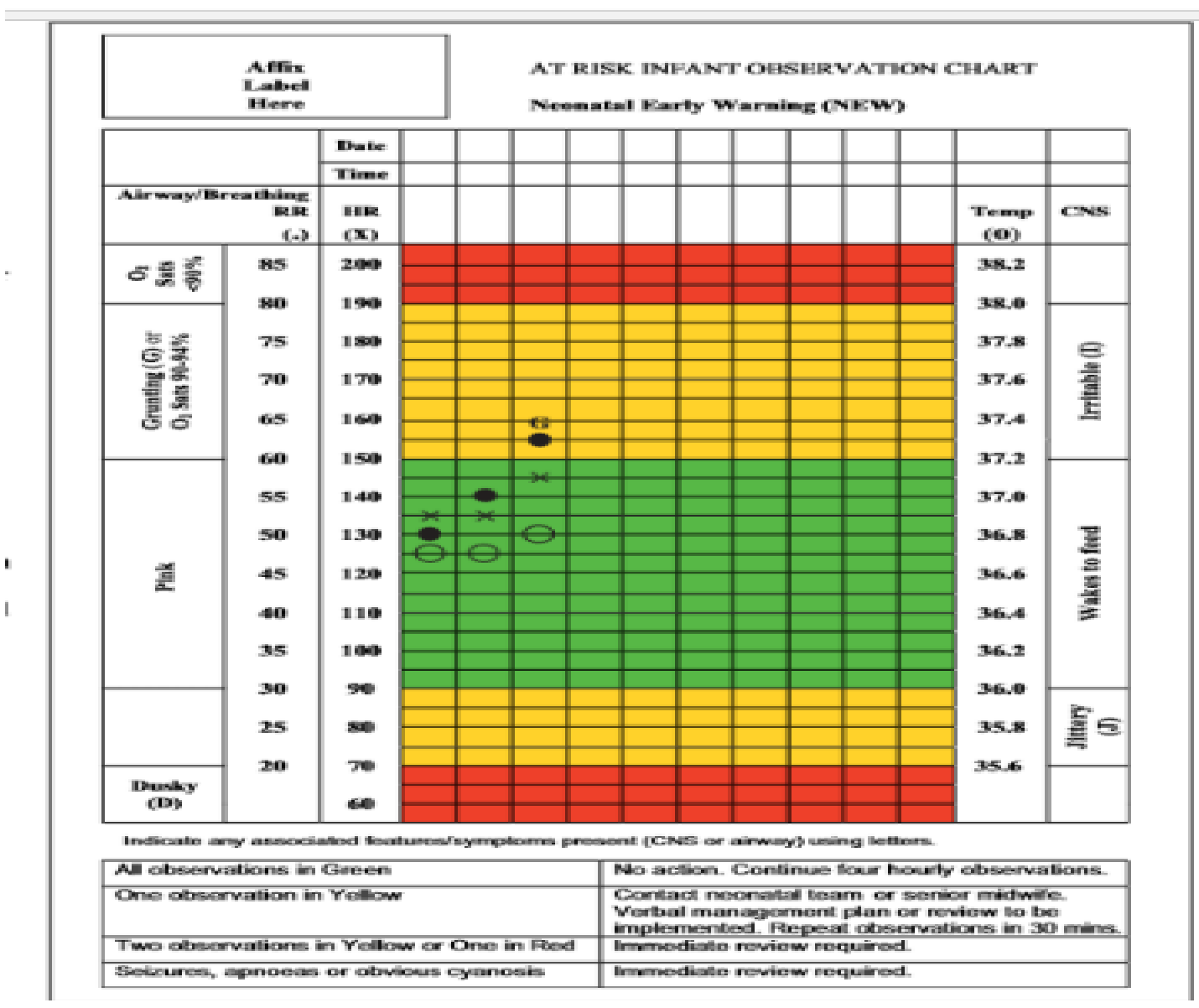

Gambar 1. Chart Newborn Early Warning (Roland et al., 2010)

Neonatal Early Warning Score (NEWS) merupakan sistem pelacakan dan identifikasi dari pencatatan tanda vital dan terdapat rentang angka penilaian terhadap hasil yang berada diluar batas normal, kemudian total penjumlahan dari masing-masing penilaian akan memberikan identifikasi sejauh mana kondisi perburukan klinis yang terjadi pada neonatal. Parameter yang digunakan dalam perangkat observasi ini adalah laju nafas, denyut jantung, saturasi oksigen, suhu tubuh, dan usaha nafas (Assessment, 2015) atau tingkat kesadaran (Roland et al., 2010). Selain memberikan penilaian kondisi klinis, perangkat ini juga memuat panduan prosedur yang harus dilakukan oleh petugas medis dan memberikan informasi objektif yang berkelanjutan pada pemberi asuhan pelayanan neonatal. Memadukan penilaian NEWS pada monitoring rekam medis elektronik di unit perawatan intensif neonatal memberikan manfaat nilai tambah dalam mengidentifikasi neonatal terhadap 
resiko terjadinya perburukan klinis untuk penatalaksanaan yang tepat, serta memberikan evaluasi terhadap keefektifan NEWS dalam melakukan skrining masuk ke unit perawatan intensif neonatal. (Yi, 2017). Kemampuan untuk melihat perkembangan nilai kondisi klinis neonatal secara menyeluruh tidak dapat

Monitoring Heart Rate Characteristics/ Heart Rate Observation (HeRo)

Denyut jantung dan variabilitas denyut jantung (HRV) memiliki kaitan dengan beberapa tanda vital seperti laju nafas, suhu tubuh dan tekanan darah melalui refleks dari sistem saraf pusat ke pacemaker jantung. Karakterisik denyut jantung (HRC, Heart Rate Characteristics) dalam mendeteksi sepsis pada neonatal terdiri dari dua komponen yaitu variabilitas penurunan denyut jantung dan transient penurunan denyut jantung (K. D. Fairchild \& O'Shea, 2010). Denyut jantung dikontrol oleh sistem saraf otonom. Pacemaker nodus sinoatrial pada atrium kanan berespon terhadap neurotransmitter yang dilepaskan oleh saraf simpatis atau parasimpatis. Pelepasan norepinefrin dari saraf simpatis menyebabkan peningkatan denyut jantung, sedangkan asetilkolin sebagai respon bergantung pada bedside observasi tanda vital saja, melainkan memerlukan sistem perangkat lunak lainnya untuk meningkatkan efektifitas dalam memonitoring kondisi neonatal yang akurat sehingga dapat menunjang pengambilan keputusan klinis yang tepat terhadap neonatal beresiko tinggi (Roland et al., 2010).

parasimpatisnya adalah dengan menurunkan denyut jantung. Perubahan denyut jantung yang diatur oleh sistem saraf otonom sebagai respon terhadap kebutuhan fisiologis tubuh yang seimbang (K. Fairchild \& Aschner, 2012). Karakteristik denyut jantung sendiri dipengaruhi oleh tekanan darah, laju nafas dan suhu tubuh. Laju nafas mempengaruhi denyut jantung melalui fenomena seperti 'respiratory sinus arrhytmia' (merupakan respon fisiologis normaldimana inspirasi dihubungkan dengan peningkatan denyut jantung, sedangkan ekspirasi dengan penurunan denyut jantung melalui rangsangan aktifitas sistem saraf simpatis dan parasimpatis) dan 'cardiorespiratory coupling' (siklus denyut jantung secara konsisten terjadi pada fase yang sama dengan siklus pernapasan). Suhu tubuh 
juga mempengaruhi denyut jantung (hipotermia dapat menimbulkan bradikardia dan hipertermia menyebabkan takikardia), namun hanya memiliki dampak minimal pada variabilitas denyut jantung (K. Fairchild \& Aschner, 2012). Bedside monitor di unit perawatan intensif memberikan rekaman data tanda vital pasien secara real time, namun masih belum terdapatnya analisis pola perubahan tanda vital, terkait dengan impending perburukan klinis serta analisis dari integrasi dari beragam tanda vital $(\mathrm{K}$. Fairchild \& Aschner, 2012). Sehingga, dengan penambahan analisa varian fisiologis pada neonatal dapat memberikan informasi tambahan dalam identifikasi dini kondisi perburukan klinis yang mungkin terjadi pada neonatal. Monitoring 'HeRo' pada awalnya dikembangkan sebagai early warning system pada bayi prematur dengan sepsis di unit perawatan intensif neonatal. Metode ini melakukan ekstraksi data elektrokardiografi dari beberapa data monitor yang digunakan di NICU, serta tidak menambahkan sensor maupun alat lain yang ditempelkan pada tubuh bayi. Penilaian dengan menggunakan metode 'HeRo' ini dilakukan secara real-time dan ditampilkan tiap jam, serta dapat menampilkan data 12 jam sebelumnya (K. Fairchild \& Aschner, 2012).

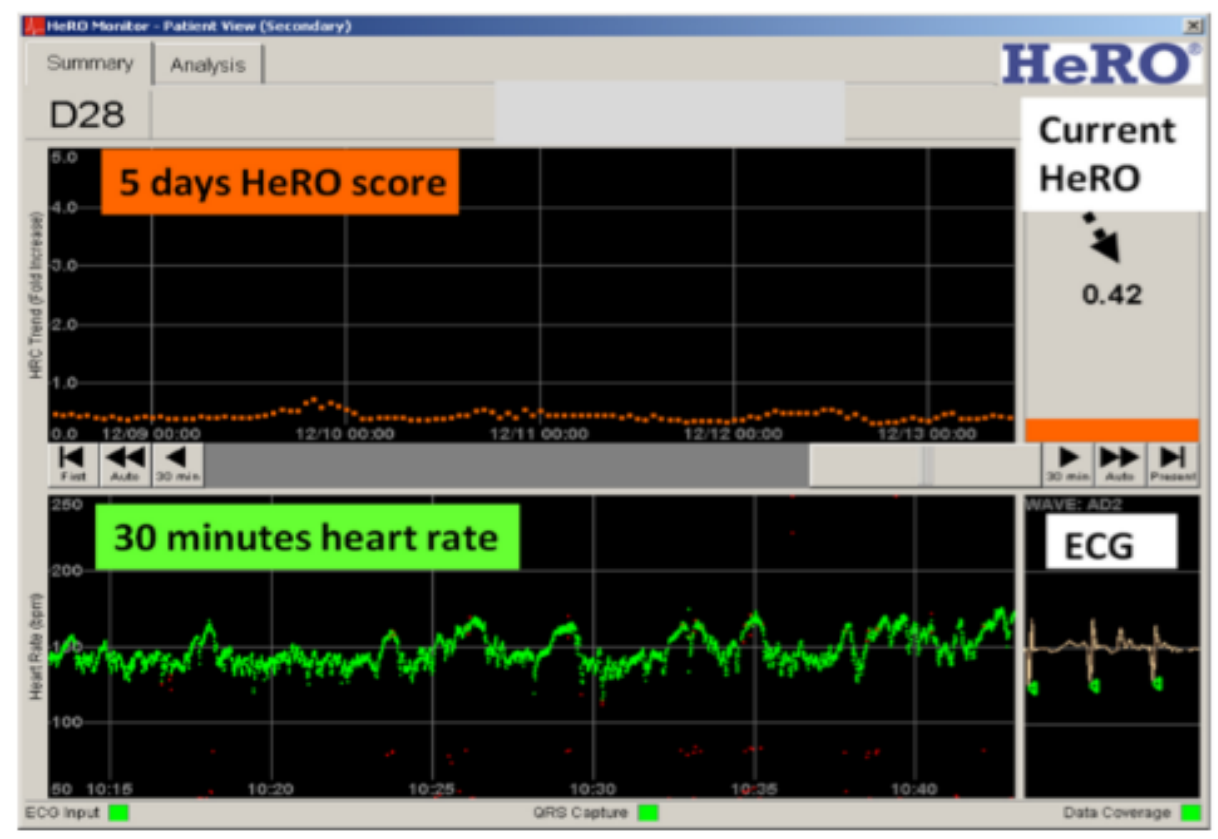

Gambar 2. Tampilan HeRo (K. Fairchild \& Aschner, 2012) 
Telah dilakukan penelitian oleh $\mathrm{K}$. Fairchild \& Aschner pada tahun 2012 di 9 NICU yang tersebar di United Stated, dengan pengambilan sampel secara random sebanyak 3003 bayi dengan berat lahir sangat rendah pada rentang kurang dari 1500 gram, yang diikuti selama 120 hari atau hingga kematian maupun alih rawat dari NICU, kemudian dilakukan randomisasi pasien yang mendapatkan pengukuran nilai dan tampilan 'HeRo' pada monitornya dengan pasien yang dilakukan pengukuran skor 'HeRo' namun tidak ditampilkan pada monitornya. Didapatkan hasil bahwa pasien yang dilakukan metode skor 'HeRo' memiliki rata-rata 2,3 hari hidup lebih lama dan tidak terpasang ventilasi mekanik dibanding pasien yang tidak dilakukan pemasangan skor 'HeRo' pada monitornya. Angka mortalitas lebih rendah $22 \%$ pada kelompok yang memiliki tampilan 'HeRo' dibandingkan dengan kelompok yang tidak memiliki tampilan 'HeRo'.

Peningkatan skor 'HeRo' juga dapat digunakan untuk memprediksi efek samping dari gangguan perkembangan syaraf. Dalam perkembangan deteksi sepsis maupun kondisi kritis lainnya dilakukan pemaduan pola laju nafas dengan denyut jantung untuk mendukung ketepatan pembuatan keputusan klinis dan meningkatkan mutu pelayanan NICU. Dibuktikan dengan menurunnya mortalitas pada neonatal yang terdiagnosa sepsis (pada neonatal yang menunjukkan hasil kultur darah yang positif) sebanyak 4\% ketika diterapkan metode skor 'HeRo' (K. Fairchild \& Aschner, 2012).

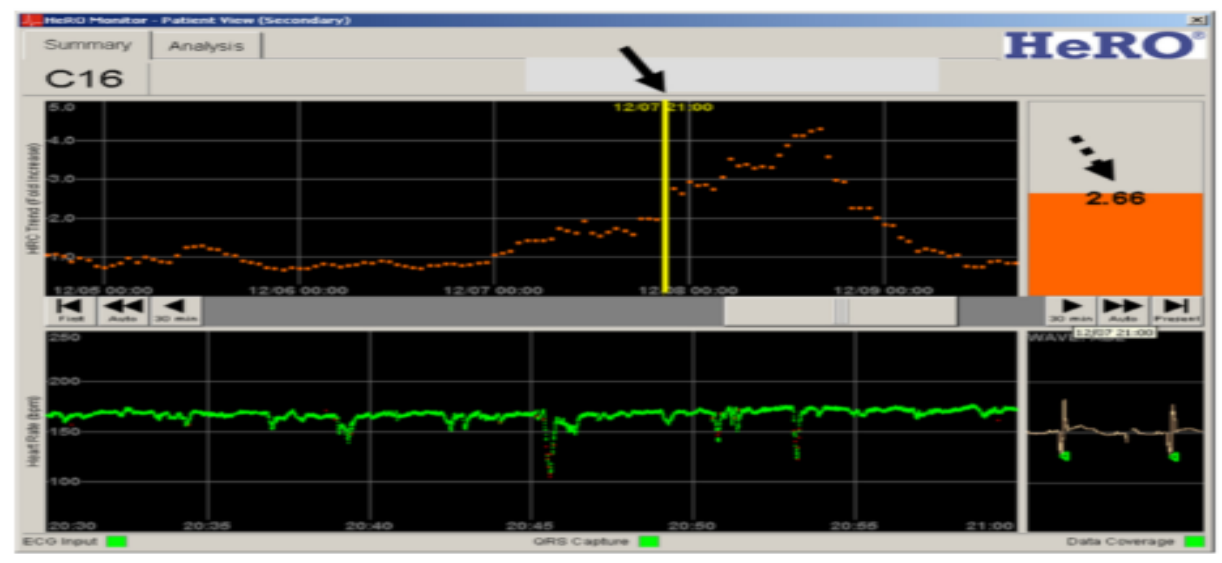

Gambar 3. Tampilan HeRo dengan abnormal karakteristik denyut jantung (K. Fairchild \& Aschner, 2012) 


\section{Pembahasan}

Skrining dengan metode komputerisasi ini memiliki kelebihan karena dapat dilakukan secara kesinambungan sehingga dapat memberi tanda peringatan pada petugas medis secara tepat ketika pasien beralih dari kondisi stabil ke perburukan klinis di unit perawatan intensif sebelum onset sepsis muncul (K. Fairchild \& Aschner, 2012).

Terdapat kekurangan pada penilaian 'HeRo' ini yang dikemukakan oleh Karen D. Fairchild dan Judy L Aschner (2012) dalam penelitiannya, yaitu penilaian skor 'HeRo' belum memberikan diferensiasi dari reaksi obat, penyakit jantung, trauma otak maupun pembedahan. Kekurangan lainnya adalah pada variasi nilai fisiologis dan kesulitan dalam referensi penilaian rentang nilai yang akurat pada setiap perubahan klinis (Collins et al., 2013).

Dari pembahasan singkat tentang beberapa metode early warning system secara elektronik dan penilaian 'HeRo'ini memberikan pemicu pada perawat dalam mengenali pola perubahan tanda vital yang dapat dikenali pada pasien sebelum terjadinya perburukan kondisi klinis yang membahayakan nyawa pasien. Menurut Collins et al (2013), sebagai satu dari profesi pemberi asuhan, perawat, memiliki waktu kontak yang lebih lama terhadap pasien, sehingga memungkinkan untuk mendeteksi perubahan kondisi pasien secara intensif. Dokumentasi perawat juga merupakan salah satu petunjuk dalam memberikan informasi tentang kondisi pasien dan bermanfaat untuk memprediksi henti jantung dan kematian (Collins et al., 2013).

\section{Kesimpulan}

Peningkatan realibilitas penggunaan tekhnologi sistem informasi yang ada pada rekam medis elektronik dengan penambahan skoring resiko, khususnya pada neonatal di unit perawatan intensif dalam mendeteksi dini kondisi perburukan klinis yang mungkin terjadi selanjutnya, sehingga mampu memberikan informasi yang signifikan kepada semua profesi pemberi asuhan neonatal. Penggunaan elektronik Neonatal Early Warning System (NEWS) dan monitoring skor Heart Rate Observation (HeRo) mendasarkan penilaiannya pada varian perubahan fisiologis neonatal, mampu memberikan 
manfaat pada ketepatan dan kecepatan dalam melakukan pengambilan keputusan klinis pasien, serta menurunkan angka mortalitas, morbiditas, maupun lama rawat NICU. Perawat yang memiliki waktu kontak yang lama terhadap pasien memungkinkan dalam menemukan dan melaporkan gejala awal perburukan klinis yang terjadi pada pasien, terutama melalui catatan perkembangan dan monitoring tanda vital bedside yang dilakukan perawat, diharapkan menjadi

\section{Referensi}

Assessment, O. (2015). Canberra Hospital and Health Services Clinical Procedure Occupational Assessment , Screening and Vaccination, 1-47.

Collins, S. A., Cato, K., Albers, D., Scott, K., Stetson, P. D., Bakken, S., \& Vawdrey, D. K. (2013). Relationship between nursing documentation and patients' mortality. American Journal of Critical Care, 22(4), 306-313. https://doi.org/10.4037/ajcc201342 6

Davison, K. K., \& Birch, L. L. (2008). NIH Public Access, 64(12), 2391- salah satu data objektif yang mampu memberikan gambaran informasi kondisi klinis pasien yang berkelanjutan dan menyeluruh.

\section{Rekomendasi}

Menjadi referensi pada pelayanan perawatan intensif neonatal di Indonesia dalam mengembangkan tekhnologi sistem informasi neonatal terutama untuk mengidentifikasi dini kondisi perburukan klinis yang mungkin terjadi pada neonatal.

2404.

https://doi.org/10.1038/jid.2014.37

Ellsworth, M. A., Lang, T. R., Pickering, B. W., \& Herasevich, V. (2014). Clinical data needs in the neonatal intensive care unit electronic medical record. BMC Medical Informatics and Decision Making, 14(1).

https://doi.org/10.1186/1472-694714-92

Fairchild, K., \& Aschner. (2012). HeRO monitoring to reduce mortality in NICU patients. Research and Reports in Neonatology, 65. https://doi.org/10.2147/RRN.S325 70 
Fairchild, K. D., \& O'Shea, T. M. (2010). Heart Rate Characteristics: Physiomarkers for Detection of Late-Onset Neonatal Sepsis. Clinics in Perinatology, 37(3), 581-598.

https://doi.org/10.1016/j.clp.2010.0 6.002

Jones, S., Mullally, M., Ingleby, S., Buist, M., Bailey, M., \& Eddleston, J. M. (2011). Bedside electronic capture of clinical observations and automated clinical alerts to improve compliance with an Early Warning Score protocol. Critical Care and Resuscitation, 13(2), 83-88.

Kim, U. O., Brousseau, D. C., \& Konduri, G. G. (2008). Evaluation and Management of the Critically Ill Neonate in the Emergency Department. Clinical Pediatric Emergency Medicine, 9(3), 140148.

https://doi.org/10.1016/j.cpem.200 8.06 .003

Paliwoda, M., \& New, K. (2015). Neonatal early warning tools: A literature review (Vol. 18). Retrieved from http://remote-
lib.ui.ac.id:2247/ContentServer.asp $? \mathrm{~T}=\mathrm{P} \& \mathrm{P}=\mathrm{AN} \& \mathrm{~K}=109821629 \& \mathrm{~S}=$ $\mathrm{R} \& \mathrm{D}=$ rzh\&EbscoContent $=\mathrm{dGJyM}$ Mvl7ESep7M4zdnyOLCmr1Cepr RSrq\%2B4S7GWxWXS\&Content Customer=dGJyMPGnrkqurrJJueP fgeyx44Dt6fKF49oA

Roland, D., Madar, J., \& Connolly, G. (2010). The Newborn Early Warning (NEW) system: development of an at-risk infant intervention system. Infant, 6(4), 116-120. Retrieved from https://pdfs.semanticscholar.org/ed bc/06260ef4876c13c172f6610d037 3c8949319.pdf

Schwartz, S. M. (2016). Can an automated early warning system derived from continuous physiologic monitoring prevent disaster? Journal of Thoracic and Cardiovascular Surgery, 152(1), 34. https://doi.org/10.1016/j.jtcvs.2016 .04 .014

Yi, C. M. (2017). Chan Man Yi, NC (Neonatal Care) Dept. of Paed. \& A.M., PMH 16 May 2017, (May). 